\title{
Soluble Neuropilin-1 is an independent marker of poor prognosis in early breast cancer
}

\author{
Tilman D. Rachner ${ }^{1,2,4}$ (1) Sabine Kasimir-Bauer ${ }^{3} \cdot$ Andy Goebel $^{1,2,5} \cdot$ Kati Erdmann $^{5,6} \cdot$ Oliver Hoffmann $^{3}$. \\ Martina Rauner ${ }^{1,2,5} \cdot$ Lorenz C. Hofbauer $^{1,2,5} \cdot$ Rainer Kimmig $^{3} \cdot$ Ann-Kathrin Bittner $^{3}$
}

Received: 17 February 2021 / Accepted: 7 April 2021 / Published online: 21 April 2021

(c) The Author(s) 2021

\begin{abstract}
Background Neuropilin-1 (NRP-1) is a transmembrane protein that acts as a multifunctional non-tyrosine kinase receptor with an established role in development and immunity. NRP-1 also regulates tumor biology, and high expression levels of tissue NRP-1 have been associated with a poor prognosis. Recently, ELISA-based quantification of soluble NRP-1 (sNRP-1) has become available, but little is known about the prognostic value of sNRP-1 in malignancies.

Materials and methods We measured sNRP- 1 in the serum of 509 patients with primary early breast cancer (BC) at the time of diagnosis using ELISA.

Results Mean serum values of sNRP-1 were $1.88 \pm 0.52 \mathrm{nmol} / 1(=130.83 \pm 36.24 \mathrm{ng} / \mathrm{ml})$. SNRP-1 levels weakly correlated with age, and were higher in peri- and postmenopausal patients compared to premenopausal patients, respectively $(p<0.0001)$. Low levels of sNRP-1 were associated with a significant survival benefit compared to high sNRP-1 levels at baseline ( $p=0.005$; HR 1.94; 95\% CI 1.23-3.06). These findings remained significant after adjustment for tumor stage including lymph node involvement, grading, hormone receptor, HER2 status, and age ( $p=0.022$; HR 1.78; 95\% CI 1.09-2.91). Conclusion Our findings warrant further investigations into the prognostic and therapeutic potential of sNRP-1 in BC.
\end{abstract}

Keywords Neuropilin- $1 \cdot$ Breast cancer $\cdot$ Prognosis

\section{Introduction}

Breast cancer (BC) is the most common cancer in women worldwide. Despite major improvements in diagnosis, treatment and a 5-year overall survival (OS) rate of $87 \%$,

Tilman D. Rachner

tilman.rachner@uniklinikum-dresden.de

1 Division of Endocrinology and Metabolic Bone Diseases, Diabetes and Bone Diseases, Department of Medicine III, TU Dresden, Fetscherstraße 74, 01307 Dresden, Germany

2 Center for Healthy Ageing, Department of Medicine III, TU Dresden, Dresden, Germany

3 Department of Gynecology and Obstetrics, University Hospital Essen, University of Duisburg-Essen, Essen, Germany

4 German Cancer Consortium (DKTK), Dresden and German Cancer Research Center (DKFZ), Heidelberg, Germany

5 Department of Urology, TU Dresden, Dresden, Germany

6 National Center for Tumor Diseases (NCT), Dresden, Germany approximately $8 \%$ of the patients develop distant metastasis within 5 years after primary diagnosis, showing a great variety depending on the genetic background, tumor stage, lymph node involvement as well as proliferation index of the primary tumor (Ki67) (Hölzel et al. 2017). Currently, only a few prognostic and therapeutic targets have been identified and further markers are needed to identify patients at high risk of recurrence and to define new specific targets for affected patients (Perez-Gracia et al. 2017).

Neuropilin-1 (NRP-1), also known as CD304 or BDCA4 , is a transmembrane protein and a multifunctional nontyrosine kinase receptor that plays an established role in development and immunity (Pellet-Many et al. 2008; Romeo et al. 2002). NRP-1 is expressed by endothelial cells as well as other cell types and was first identified as a receptor for class 3 semaphorins (SEMA3) (Kolodkin et al. 1997). It is assumed that NRP-1 promotes cancer by binding to molecules involved in angiogenesis and epithelial-to-mesenchymal Transition (EMT) (Soker et al. 1998; Chu et al. 2014). It is known to act as a co-receptor for a vascular endothelial growth factor (VEGF), placenta growth factor (PIGF), 
transforming growth factor $\beta 1$ (TGF- $\beta 1$ ), hepatocyte growth factor (HGF), platelet-derived growth factor (PDGF) and fibroblast growth factors (FGFs) among others (Mamluk et al. 2002; Glinka and Prudhomme 2008; Hu et al. 2007; Cao et al. 2010). The interaction of NRP-1 with VEGF and VEGFR2 has been of special interest since it results in an enhanced signaling and promotion of angiogenesis. In the past years, NRP-1 has also been associated with malignant transformation and cancer progression (reviewed in (Prudhomme and Glinka 2012)).

NRP-1 is also expressed in BC cells and has been associated with effects on cell invasion, survival, and migration (Bachelder et al. 2002) and negatively correlates with patient survival (Ghosh et al. 2008; Jubb et al. 2012). Furthermore, NRP-1 expression in BC tissue has been linked to lymph node metastasis (Seifi-Alan et al. 2018). This data is consistent with further studies, showing a correlation of NRP-1 expression in tumor tissue and aggressiveness of BC (Luo et al. (2016)).

Soluble NRP-1 (sNRP-1) can be successfully quantified using ELISA-based approaches (Lu et al. 2009) and more recently, plasma and tumor tissue levels of NRP-1 were found to be upregulated in node-positive patients with BC and advanced metastatic disease (Naik et al. 2017). However, little is known about the prognostic value of serum NRP-1 levels in affected patients. This study aimed to assess sNRP-1 levels in serum samples of women with early BC at the time of the first diagnosis and to investigate whether these findings are associated with the prognosis and clinical parameters.

\section{Patients and methods}

\section{Patient population and study design}

This retrospectively assessed study was conducted in a wellestablished cohort of 509 early BC patients as previously described (Rachner et al. 2018, 2020). Briefly, patients were diagnosed between 2004 und 2009 and serum samples were obtained prior to any systemic or surgical therapy after written informed consent using a protocol approved by the clinical Ethics committee of the University Hospital Essen (05/2856). To be eligible for study inclusion, patients were required to have histologically proven $\mathrm{BC}$, no severe uncontrolled co-morbidities or medical conditions, no further present malignancies or malignancies in the past. Treatment was performed according to the current guidelines at the time including adjuvant chemotherapy (anthracyclines, 5-fluorouracil, taxanes, cyclophosphamide), anti-hormonal therapy in the case of hormone-responsive tumors (tamoxifen or an aromatase inhibitor), trastuzumab in the case of HER2-positivity (following FDA approval in 2006) and radiotherapy. Patients receiving neo-adjuvant chemotherapy were not included. Tumor type, TNM-staging and grading were assessed at the Institute of Pathology of the University Hospital Essen as part of the West German Comprehensive Cancer Center.

\section{Sampling of serum}

Blood was collected with an S-Monovette (Sarstedt AG \& Co.) from each patient, stored at $4{ }^{\circ} \mathrm{C}$ and processed within $4 \mathrm{~h}$ to avoid blood cell lysis. Blood fractionation was carried out by centrifugation for $10 \mathrm{~min}$ at $2500 \times \mathrm{g}$. Subsequently, 3-4 $\mathrm{ml}$ of the upper phase, constituting blood serum, were removed and frozen at $-80{ }^{\circ} \mathrm{C}$ (as previously described (Rachner et al. 2018)).

\section{Detection of sNRP-1 by ELISA}

Assessment of all serum samples was conducted at the same time. SNRP-1 was detected by ELISA (Biomedica, Vienna, Austria). With a sensitivity of $0.09 \mathrm{nmol} / \mathrm{l}(=6.3 \mathrm{ng} / \mathrm{ml})$ and an in-between and within-run precision of $<12 \% \mathrm{CV}$ this 1 day, $4 \mathrm{~h}$ assay detects free and ligand-bound SNRP-1.

Briefly, $10 \mu \mathrm{l}$ of the sample was used per well and the ELISA was conducted according to the manufacturer's protocol. After pipetting the standards, controls and samples into the respective wells of the pre-dilution plate, $10 \mu \mathrm{l}$ of guanidine hydrochloride was added for $30 \mathrm{~min}$ and $200 \mu \mathrm{l}$ of assay buffer was added. In the pre-coated plate, $50 \mu \mathrm{l}$ of assay buffer was added and $50 \mu \mathrm{l}$ of the samples from the pre-dilution plate was transferred. Following this step, $50 \mu \mathrm{l}$ of biotinylated anti-NRP-1 antibody was added to each well and plates were incubated for $2 \mathrm{~h}$ at room temperature. Following a number of washing steps, $150 \mu \mathrm{l}$ of conjugate was added to each well and plates were incubated for another hour. Following another set of washing steps, $150 \mu \mathrm{l}$ of substrate was given into each well and after $30 \mathrm{~min}$ of incubation, $50 \mu$ lof stop solution was applied. Absorbance was measured immediately at $450 \mathrm{~nm}$ with reference at $630 \mathrm{~nm}$ using FLUOstar Omega (BMG Labtech, Ortenberg, Germany).

\section{Statistical analysis}

Results are presented as the standard deviation of the mean unless otherwise stated. Groups of two were assessed by the Mann-Whitney- $U$-Test, groups of three or more were assessed by ANOVA. Correlation analysis was performed using the Pearson correlation coefficient.

Samples were divided into two groups at the median SNRP- 1 value and classified as SNRP- $1^{\text {high }}$ and SNRP- $1^{\text {low }}$. Kaplan-Meier curves were assessed using the log-rank 
(Mantel-Cox) test. BC-specific survival (BCSS) was defined as time between diagnosis of the primary tumor and death directly related to the disease. Multivariate Cox regression analyses were performed to identify prognostic factors for the different survival endpoints. The multivariate Cox's regression models were adjusted to known clinical prognostic factors in BC patients. $p$ values $<0.05$ were considered statistically significant.

\section{Results}

From the 509 patients included in this cohort, 506 samples were available for assessment and valid sNRP-1 measurements were obtained in all cases (506/506). Mean serum values of sNRP-1 were $1.88 \pm 0.52 \mathrm{nmol} / \mathrm{l}(=130.83 \pm 36.24 \mathrm{ng} /$ $\mathrm{ml})$. There was no significant difference in samples when stratifying according to tumor size (T) or lymph node involvement $(\mathrm{N})$. Furthermore, the estrogen receptor (ER) status of the tumor did not influence sNRP-1 levels).

SNRP-1 levels were significantly higher in the serum of patients who were older than 60 years of age at the time of diagnosis, compared to younger patients $(1.96 \pm 0.51$ vs. $1.79 \pm 0.52 ; p<0.0001)$. In line with this finding, sNRP-1 levels were significantly higher in peri- and postmenopausal patients compared to premenopausal patients, respectively (Table 1). There was no significant difference between periand postmenopausal samples. Age and sNRP-1 levels were weakly positively correlated $\left(p<0.0001, r 0.24, r^{2} 0.06\right)$ (Fig. 1).

\section{Soluble NRP-1 is an independent prognostic marker for $B C$ specific survival}

Follow-up was available for 501 of the 506 patients, with five patients lost to follow-up. Mean follow-up was 8.6 years (range 0.2-13.6 years) and 74 cases of BC-specific deaths were documented during that time. When stratifying patients according to their sNRP-1 levels into a sNRP-1 ${ }^{\text {high }}$ and SNRP- $1^{\text {low }}$ group, there was a significant survival benefit for patients who had low sNRP-1 levels at baseline ( $p=0.005$; HR 1.94; 95\%CI 1.23-3.06). While there were 47 documented cases of BC-specific death in the sNRP- $1^{\text {high }}$ group, only 27 cases were seen in the SNRP- $1^{\text {low }}$ cohort despite a slightly longer mean follow-up (8.08 vs. 9.04 years, respectively) (Fig. 2).

Multivariate Cox regression analyses adjusted for tumor stage including lymph node involvement, grading, hormone receptor and HER2 status revealed SNRP-1 to be an independent prognostic marker for BCSS ( $p=0.006$; HR 1.98 ; 95\% CI 1.22-3.21).

Since we saw a positive correlation between age and sNRP-1 levels, we also included age in the multivariate
Table 1 Soluble NRP-1 levels in breast cancer patients

\begin{tabular}{|c|c|c|c|}
\hline & Patients $(n)$ & sNRP-1 (nmol/1) & $p$ value \\
\hline \multicolumn{4}{|l|}{ Age (years) } \\
\hline$<60$ & 243 & $1.79 \pm 0.52$ & \multirow[t]{2}{*}{0.0001} \\
\hline$>60$ & 263 & $1.96 \pm 0.51$ & \\
\hline \multicolumn{4}{|l|}{ Menopausal status } \\
\hline Premenopausal & 72 & $1.65 \pm 0.50$ & \multirow{3}{*}{$\begin{array}{l}<0.0001 \text { vs. post- } \\
0.04 \text { vs. post- }\end{array}$} \\
\hline $\begin{array}{l}\text { Perimenopau- } \\
\text { sal }\end{array}$ & 63 & $1.77 \pm 0.48$ & \\
\hline $\begin{array}{l}\text { Postmenopau- } \\
\text { sal }\end{array}$ & 371 & $1.94 \pm 0.52$ & \\
\hline \multicolumn{4}{|l|}{ Histology } \\
\hline Ductal & 383 & $1.89 \pm 0.52$ & \multirow[t]{3}{*}{$\mathrm{ns}$} \\
\hline Lobular & 68 & $1.88 \pm 0.54$ & \\
\hline Others & 55 & $1.84 \pm 0.47$ & \\
\hline \multicolumn{4}{|l|}{ Tumor size } \\
\hline pT1 & 320 & $1.87 \pm 0.54$ & \multirow[t]{3}{*}{ ns } \\
\hline pT2 & 158 & $1.88 \pm 0.50$ & \\
\hline pT3-4 & 24 & $2.03 \pm 0.46$ & \\
\hline \multicolumn{4}{|l|}{ Nodal status } \\
\hline Node negative & 338 & $1.86 \pm 0.52$ & \multirow[t]{2}{*}{$\mathrm{ns}$} \\
\hline Node positive & 158 & $1.92 \pm 0.52$ & \\
\hline \multicolumn{4}{|l|}{ Grading } \\
\hline I & 88 & $1.88 \pm 0.47$ & \multirow[t]{3}{*}{$\mathrm{ns}$} \\
\hline II & 269 & $1.87 \pm 0.51$ & \\
\hline III & 148 & $1.89 \pm 0.57$ & \\
\hline \multicolumn{4}{|l|}{ ER status } \\
\hline Negative & 94 & $1.91 \pm 0.66$ & \multirow[t]{2}{*}{$\mathrm{ns}$} \\
\hline Positive & 411 & $1.87 \pm 0.48$ & \\
\hline \multicolumn{4}{|l|}{ PR status } \\
\hline Negative & 135 & $1.88 \pm 0.62$ & \multirow[t]{2}{*}{ ns } \\
\hline Positive & 370 & $1.88 \pm 0.48$ & \\
\hline \multicolumn{4}{|l|}{ Her2 status } \\
\hline Negative & 423 & $1.88 \pm 0.50$ & \multirow[t]{2}{*}{ ns } \\
\hline Positive & 80 & $1.86 \pm 0.64$ & \\
\hline
\end{tabular}

Values of sNRP-1 are given in nmol/l. $n s$ not significant; Differences to total number of patients $(n=506)$ may occur, since for some characteristics information may be missing

Cox regression analyses in addition to the factors mentioned above. Here, sNRP-1 remained an independent prognostic marker for BCSS ( $p=0.022$; HR $1.78 ; 95 \% \mathrm{CI}$ 1.09-2.91) (Fig. 3). Results also remained significant when menopausal status was included in addition to age and the other parameters ( $p=0.015$; HR 1.86; 95\%CI 1.13-3.07). 


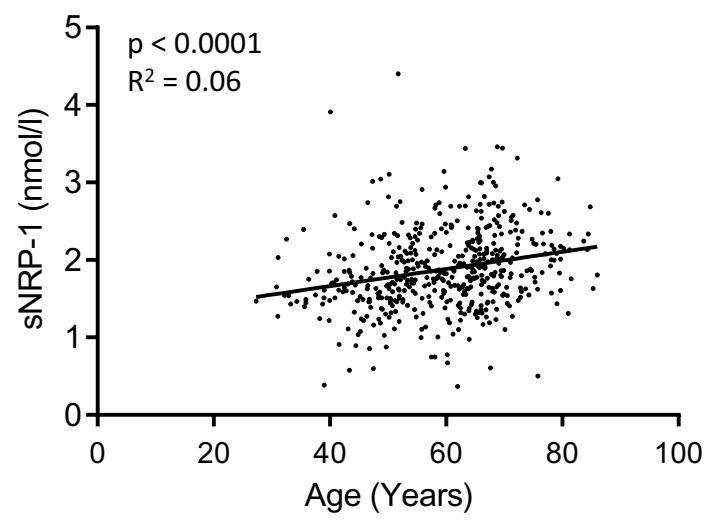

Fig. 1 sNRP-1 levels weakly correlate with age. sNRP-1 serum levels positively correlate with the age of assessed subjects

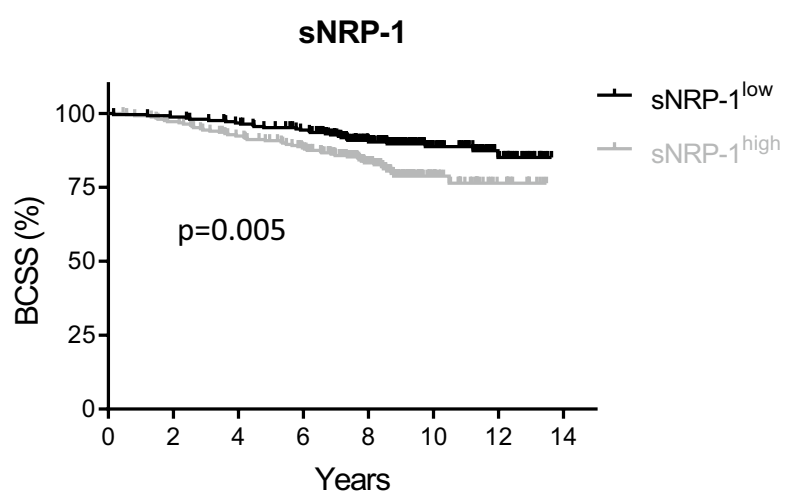

Subjects at risk

$\begin{array}{lllllllll}\text { sNRP-1 low } & 250 & 247 & 241 & 230 & 165 & 86 & 37 & 0\end{array}$

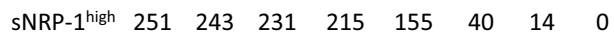

Fig. 2 sNRP-1 is a prognostic marker for breast cancer-specific survival. Baseline levels of sNRP-1 were measured in 506 patients diagnosed with primary, non-metastatic breast cancer using ELISA. The patient cohort was divided at the median into a SNRP- $1^{\text {high }}$ and SNRP$1^{\text {low }}$ group. Kaplan-Meier curve for breast cancer-specific survival (BCSS) was assessed using the log-rank (Mantel-Cox) test based on survival data of 501 patients

\section{Discussion}

In the past years, the role of NRP-1 in cancer progression has gained significant interest with studies showing a tumor promoting or prognostic role in several malignancies including pancreas (Ben et al. 2014), liver (Xu and Xia 2013), gastric (Kang et al. 2020), colon (Parikh et al. 2004), lung (Roche et al. 2002) and breast cancer (Ferrario et al. 2006). Consequently, NRP-1 is considered a potential target for cancer therapy (Ding et al. 2018). More precisely, as an enhancer of VEGF activity and mediator of endothelial cell adhesion to extracellular matrix proteins,
NRP-1 has been considered as a potential antiangiogenic target.

Angiogenesis is an essential step to provide the basis for tumor progression at a local and metastatic level. In pancreatic ductal adenocarcinoma, microvessel density was significantly higher in the tumors with high NRP-1 expression than that in the tumors with low NRP-1 expression (Ben et al. 2014).

In prostate cancer, shRNA-mediated suppression of NRP-1 regulated the invasiveness and metastatic dissemination of cancer cells in vivo and NRP-1 expression was established as an independent marker of metastasis and cancer-specific survival (Tse et al. 2017). Using a Neuropilin-1 transmembrane domain interfering peptide, the proliferation of BC cell lines was inhibited and tumor size was reduced in murine models of breast cancer (Arpel et al. 2016). Furthermore, a humanized monoclonal antibody against NRP-1 is currently being investigated in clinical trials (NCT00747734, NCT00954642).

As an additional approach, the use of sNRP-1 as a decoy receptor has been investigated in animal models of tumor growth. SNRP-1 inhibited tumor angiogenesis and growth in murine granulocytic sarcoma (chloroma) (Gagnon et al. 2000) and significantly prolonged survival in a murine model of systemic leukemia (Schuch et al. 2002). However, the majority of studies has investigated tissue expression of NRP-1 rather than its soluble form. The perception that sNRP-1 has opposing effects to membrane bound NRP-1 (Uniewicz et al. 2011) would imply that high levels of sNRP-1 would favor a better prognosis in malignancies. However, there is currently very limited data assessing the prognostic value of sNRP-1. In a study in early cervical cancer and cervical intraepithelial neoplasia conducted in a small cohort of 56 patients, sNRP-1 correlated with stage and more importantly showed a significant correlation with tissue expression (Yang et al. 2015). More recently, circulating and tumor tissue expression of NRP-1 were found to increase in advanced nodal and metastatic BC (Naik et al. 2017). These findings suggest that high levels of circulating sNRP-1 may in fact be a reflection of its level of tissue expression. This would imply that measurement of circulating SNRP-1 may be a more convenient way to determine NRP-1 activity than the more invasive way of analyzing tissue. Recent data also suggest that changes of sNRP-1 following the initiation of an anticancer-therapy may be useful for monitoring treatment response. In patients receiving neo-adjuvant chemotherapy for locally advanced BC, significantly increased plasma sNRP-1 levels were observed in patients with a pathological partial response $(p=0.018)$ (Al-Zeheimi et al. 2019).

This study lacks the possibility to analyze corresponding tissue expression of NRP-1 in the breast tumors. However, in this large and well-characterized cohort, the measurement of 


\begin{tabular}{|c|c|c|c|c|c|c|c|c|c|}
\hline & \multicolumn{3}{|c|}{ Univariate analyses } & \multicolumn{3}{|c|}{ Multivariate analyses ${ }^{1}$} & \multicolumn{3}{|c|}{ Multivariate analyses ${ }^{2}$} \\
\hline & $\mathrm{HR}$ & $95 \% \mathrm{Cl}$ & $p$ value & $\mathrm{HR}$ & $95 \% \mathrm{Cl}$ & $p$ value & HR & $95 \% \mathrm{Cl}$ & $p$ value \\
\hline sNF & 1.94 & $1.23-3.06$ & 0.005 & 1.98 & $1.22-3.21$ & 0.006 & 1.78 & $1.09-2.91$ & 0.022 \\
\hline
\end{tabular}

1) Adjusted for tumor stage (T), lymph node involvement $(N)$, grade $(G)$ and the expression of estrogen, progesterone receptor and HER2

2) Adjusted for tumor stage $(T)$, lymph node involvement $(N)$, grade $(G)$ and the expression of estrogen, progesterone receptor and HER2 + age

Fig. 3 sNRP-1 is an independent prognostic marker in breast cancer. Univariate and multivariate Cox regression analyses for BCSS dependent on SNRP-1 levels and clinicopathological parameters were performed. Multivariate analyses adjusted for tumor stage (T), lymph node involvement $(\mathrm{N})$, grade $(\mathrm{G})$ and the expression of estrogen, progesterone receptor and HER2 as well as age confirmed the independ-

sNRP-1 was shown to be an independent prognostic marker for cancer survival in BC and further studies are warranted to increase our knowledge of how sNRP-1 may be utilized as a prognostic and/or therapeutic target in $\mathrm{BC}$.

Author contributions Study Design: AKB, OH and TDR. Study conduct: AG, AKB, OH and TDR. Data collection: AKB, OH, RK, SKB. Data analysis: AG, AKB, KE, OH, and TDR. Data interpretation: AG, AKB, LCH, MR, OH, SKB, and TDR. Drafting Manuscript: AG, AKB, $\mathrm{OH}, \mathrm{SKB}$, and TDR. Revising manuscript content: AG, AKB, KE, $\mathrm{LCH}, \mathrm{OH}, \mathrm{RK}, \mathrm{SKB}$, and TDR. Approving final version of manuscript: AG, AKB, MR, KE, LCH, OH, RK, SKB, and TDR. TDR takes responsibility for the integrity of the data analysis.

Funding Open Access funding enabled and organized by Projekt DEAL. This work was supported by grants to LCH (HO 1875/27-1) and TDR (RA 2151/5-1) and SPP-2084 $\mu$ BONE to TDR, MR, AG and LCH from the Deutsche Forschungsgemeinschaft as well as by the Deutsche Krebshilfe to TDR and AG as part of the Mildred-Scheel Nachwuchszentrum.

\section{Declarations}

Conflict of interest SKB is a consultant for QIAGEN, Hilden, Germany. All other authors declare no potential conflicts of interest.

Ethical approval All procedures performed in studies involving human participants were in accordance with the ethical standards of the institutional and/or national research committee and with the 1964 Helsinki declaration and its later amendments or comparable ethical standards.

Informed consent Samples of patients were obtained before therapy after written informed consent from all subjects using protocols ent prognostic value of SNRP-1 in breast cancer. All included parameters were used in a binominal fashion (sNRP-1: high vs low; tumor stage: pT4, pT3, pT2 vs pT1; lymph node involvement: positive vs negative; grade: III, II vs I; hormone receptor and HER2 status: positive vs negative; age: $>60$ vs $<60$ )

approved by the clinical ethics committee of the University Hospital Essen (05/2856).

Open Access This article is licensed under a Creative Commons Attribution 4.0 International License, which permits use, sharing, adaptation, distribution and reproduction in any medium or format, as long as you give appropriate credit to the original author(s) and the source, provide a link to the Creative Commons licence, and indicate if changes were made. The images or other third party material in this article are included in the article's Creative Commons licence, unless indicated otherwise in a credit line to the material. If material is not included in the article's Creative Commons licence and your intended use is not permitted by statutory regulation or exceeds the permitted use, you will need to obtain permission directly from the copyright holder. To view a copy of this licence, visit http://creativecommons.org/licenses/by/4.0/.

\section{References}

Al-Zeheimi N, Naik A, Bakheit CS, Al Riyami M, Al Ajarrah A, Al Badi $S$ et al (2019) Neoadjuvant chemotherapy alters neuropilin-1, PIGF, and SNAI1 expression levels and predicts breast cancer patients response. Front Oncol 9:323

Arpel A, Gamper C, Spenlé C, Fernandez A, Jacob L, Baumlin N et al (2016) Inhibition of primary breast tumor growth and metastasis using a neuropilin-1 transmembrane domain interfering peptide. Oncotarget 7:54723-54732

Bachelder RE, Wendt MA, Mercurio AM (2002) Vascular endothelial growth factor promotes breast carcinoma invasion in an autocrine manner by regulating the chemokine receptor CXCR4. Cancer Res 62:7203-7206

Ben Q, Zheng J, Fei J, An W, Li P, Li Z et al (2014) High neuropilin 1 expression was associated with angiogenesis and poor overall survival in resected pancreatic ductal adenocarcinoma. Pancreas 43:744-749 
Cao S, Yaqoob U, Das A, Shergill U, Jagavelu K, Huebert RC et al (2010) Neuropilin-1 promotes cirrhosis of the rodent and human liver by enhancing PDGF/TGF- $\beta$ signaling in hepatic stellate cells. J Clin Invest 120:2379-2394

Chu W, Song X, Yang X, Ma L, Zhu J, He M et al (2014) Neuropilin-1 promotes epithelial-to-mesenchymal transition by stimulating nuclear factor-kappa B and is associated with poor prognosis in human oral squamous cell carcinoma. PLoS ONE 9:e101931

Ding Y, Zhou J, Wang S, Li Y, Mi Y, Gao S et al (2018) Antineuropilin-1 monoclonal antibody suppresses the migration and invasion of human gastric cancer cells via Aktdephosphorylation. ExpTher Med 16:537-546

Ferrario C, Hostetter G, Bouchard A, Huneau M-C, Mamo A, Basik $M$ (2006) Expression of neuropilin-1 and related proteins in breast cancer. Proc Amer Assoc Cancer Res 47

Gagnon ML, Bielenberg DR, Gechtman ZE, Miao H-Q, Takashima S, Soker S et al (2000) Identification of a natural soluble neuropilin-1 that binds vascular endothelial growth factor: in vivo expression and antitumor activity. Proc Natl AcadSci 97:2573-2578

Ghosh S, Sullivan CAW, Zerkowski MP, Molinaro AM, Rimm DL, Camp RL et al (2008) High levels of vascular endothelial growth factor and its receptors (VEGFR-1, VEGFR-2, neuropilin-1) are associated with worse outcome in breast cancer. Hum Pathol 39:1835-1843

Glinka Y, Prudhomme GJ (2008) Neuropilin-1 is a receptor for transforming growth factor beta-1, activates its latent form, and promotes regulatory T cell activity. J LeukocBiol 84:302-310

Hölzel D, Eckel R, Bauerfeind I, Baier B, Beck T, Braun M et al (2017) Improved systemic treatment for early breast cancer improves cure rates, modifies metastatic pattern and shortens post-metastatic survival: 35-year results from the Munich Cancer Registry. J Cancer Res ClinOncol 143:1701-1712

Hu B, Guo P, Bar-Joseph I, Imanishi Y, Jarzynka MJ, Bogler O et al (2007) Neuropilin-1 promotes human glioma progression through potentiating the activity of the HGF/SF autocrine pathway. Oncogene 26:5577-5586

Jubb AM, Strickland LA, Liu SD, Mak J, Schmidt M, Koeppen H (2012) Neuropilin-1 expression in cancer and development. J Pathol 226:50-60

Kang JY, Gil M, Kim KE (2020) Neuropilin1 expression acts as a prognostic marker in stomach adenocarcinoma by predicting the infiltration of treg cells and M2 macrophages. J Clin Med 9:1430

Kolodkin AL, Levengood DV, Rowe EG, Tai YT, Giger RJ, Ginty DD (1997) Neuropilin is a semaphorin III receptor. Cell 90:753-762

Lu Y, Xiang H, Liu P, Tong RR, Watts RJ, Koch AW et al (2009) Identification of circulating neuropilin-1 and dose-dependent elevation following anti-neuropilin-1 antibody administration. MAbs 1:364-369

Luo M, Hou L, Li J, Shao S, Huang S, Meng D et al (2016) VEGF/ NRP-1axis promotes progression of breast cancer via enhancement of epithelial-mesenchymal transition and activation of NF- $\kappa B$ and $\beta$-catenin. Cancer Lett 373:1-11

Mamluk R, Gechtman Z, Kutcher ME, Gasiunas N, Gallagher J, Klagsbrun M (2002) Neuropilin-1 binds vascular endothelial growth factor 165, placenta growth factor-2, and heparin via its b1b2 domain. J BiolChem 277:24818-24825

Naik A, Al-Zeheimi N, Bakheit CS, Al Riyami M, Al Jarrah A, Al Moundhri MS et al (2017) Neuropilin-1 associated molecules in the blood distinguish poor prognosis breast cancer: a crosssectional study. Sci Rep 7:3301

Parikh AA, Fan F, Liu WB, Ahmad SA, Stoeltzing O, Reinmuth N et al (2004) Neuropilin-1 in human colon cancer: expression, regulation, and role in induction of angiogenesis. Am J Pathol 164:2139-2151

Pellet-Many C, Frankel P, Jia H, Zachary I (2008) Neuropilins: structure, function and role in disease. Biochem J 411:211-226

Perez-Gracia JL, Sanmamed MF, Bosch A, Patiño-Garcia A, Schalper KA, Segura V et al (2017) Strategies to design clinical studies to identify predictive biomarkers in cancer research. Cancer Treat Rev 53:79-97

Prudhomme GJ, Glinka Y (2012) Neuropilins are multifunctional coreceptors involved in tumor initiation, growth, metastasis and immunity. Oncotarget 3:921-939

Rachner TD, Kasimir-Bauer S, Göbel A, Erdmann K, Hoffmann O, Browne A et al (2018) Prognostic value of RANKL / OPG serum levels and disseminated tumor cells in nonmetastatic breast cancer. Clin Cancer Res 25:1369-1378

Rachner TD, Göbel A, Hoffmann O, Erdmann K, Kasimir-Bauer S, Breining D et al (2020) High serum levels of periostin are associated with a poor survival in breast cancer. Breast Cancer Res Treat 180:515-524

Roche J, Drabkin H, Brambilla E (2002) Neuropilin and its ligands in normal lung and cancer. AdvExp Med Biol 515:103-114

Romeo P-H, Lemarchandel V, Tordjman R (2002) Neuropilin-1 in the immune system. AdvExp Med Biol 515:49-54

Schuch G, Machluf M, Bartsch G, Nomi M, Richard H, Atala A et al (2002) In vivo administration of vascular endothelial growth factor (VEGF) and its antagonist, soluble neuropilin-1, predicts a role of VEGF in the progression of acute myeloid leukemia in vivo. Blood 100:4622-4628

Seifi-Alan M, Shams R, Bandehpour M, Mirfakhraie R, GhafouriFard S (2018) Neuropilin-1 expression is associated with lymph node metastasis in breast cancer tissues. Cancer Manag Res 10:1969-1974

Soker S, Takashima S, Miao HQ, Neufeld G, Klagsbrun M (1998) Neuropilin-1 is expressed by endothelial and tumor cells as an isoform-specific receptor for vascular endothelial growth factor. Cell 92:735-745

Tse BWC, Volpert M, Ratther E, Stylianou N, Nouri M, McGowan K et al (2017) Neuropilin-1 is upregulated in the adaptive response of prostate tumors to androgen-targeted therapies and is prognostic of metastatic progression and patient mortality. Oncogene 36:3417-3427

Uniewicz KA, Cross MJ, Fernig DG (2011) Exogenous recombinant dimeric neuropilin-1 is sufficient to drive angiogenesis. J BiolChem 286:12-23

Xu J, Xia J (2013) NRP-1 silencing suppresses hepatocellular carcinoma cell growth in vitro and in vivo. ExpTher Med 5:150-154

Yang S, Cheng H, Huang Z, Wang X, Wan Y, Cai J et al (2015) Circulating soluble neuropilin-1 in patients with early cervical cancer and cervical intraepithelial neoplasia can be used as a valuable diagnostic biomarker. Dis Markers 2015:506428

Publisher's Note Springer Nature remains neutral with regard to jurisdictional claims in published maps and institutional affiliations. 